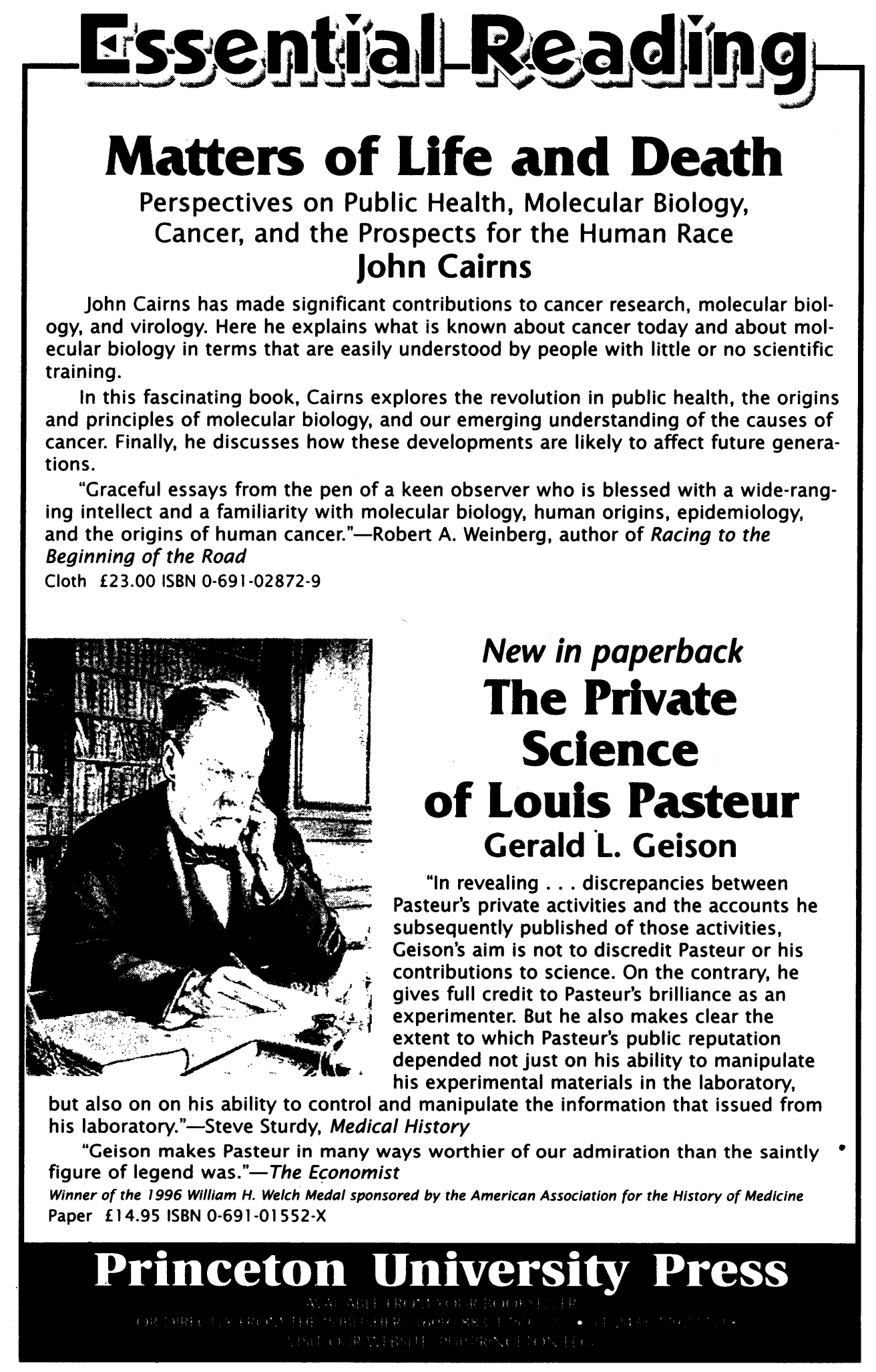


Rare Books \& Manuscripts

New Books

in the history of

Medicine \& the Sciences

BOUGH'T'SOLD·APPRAISEI)

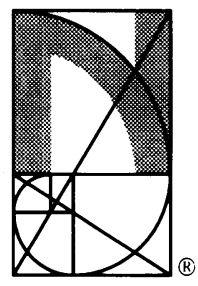

Send for our latest catalogue Jeremy Norman \& Co., Inc.

Norman Publishing

720 Market Street

San Francisco, California 94102

(415) 781-6402

FAX (415) 781-5507

e-mail: orders@jnorman.com

\section{Nigigld Chifilits}

Antiquarian books in the history of medicine and the health sciences.

Please send for my catalogue, or telephone for an appointment when in London.

5 BURLEIGH PLACE

PUTNEY

LONDON SW15 6ES

ENGLAND

Tel: 01817882664

Fax: 01817801989

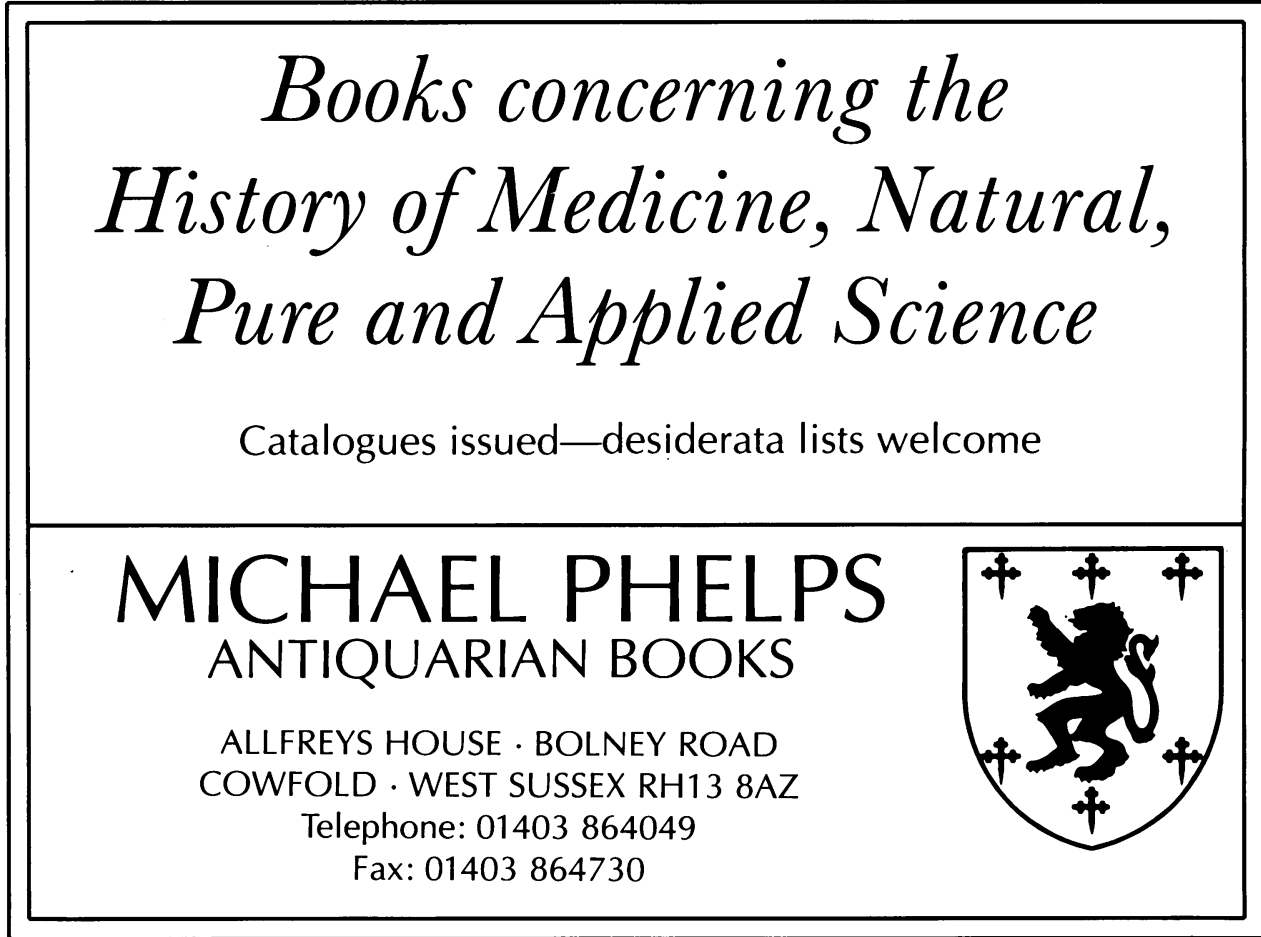

